\title{
Customizing Hybrid Products
}

\author{
Steve Benford ${ }^{1}$, Boriana Koleva ${ }^{1}$, William Preston ${ }^{1}$, Alice Angus ${ }^{2}$, Emily-Clare Thorn ${ }^{1}$, \\ Kevin Glover ${ }^{1}$ \\ University of Nottingham ${ }^{1}$ \\ Nottingham, UK \\ \{firstname.lastname\}@nottingham.ac.uk \\ Proboscis $^{2}$ \\ London, UK \\ alice@proboscis.org.uk
}

\begin{abstract}
We explore how the convergence of the digital and physical into hybrid products leads to new possibilities for customization. We report on a technology probe, a hybrid advent calendar with both paper form and digital layers of content, both of which were designed to be customizable. We reveal how over two hundred active users adapted its physical and digital aspects in various ways, some anticipated and familiar, but others surprising. This leads us to contribute concepts to help understand and design for hybrid customization - the idea of broad customization spanning physical and digital; end-to-end customization by different stakeholders along the value chain for a product; and the combination of these into customization maps.
\end{abstract}

\section{AUTHOR KEYWORDS}

Personalisation, Customisation, Hybrid products, Augmented Reality, Internet of Things, Gifting

\section{ACM Classification Keywords}

H.5.m. Information interfaces and presentation (e.g., HCI): Miscellaneous

\section{INTRODUCTION}

The idea of physical-digital hybridization has been present in HCI research for decades, running as a thread through ubiquitous computing [41]; tangible and embedded interfaces [18, 23]; augmented reality [4]; and discussions of making and crafting [21, 38]. This has led to various notions of hybridity including hybrid materials [10, 40], hybrid artefacts [8] and hybrid user experiences [9].

As part of this, previous research has explored how physical artefacts can acquire value through the accretion of digital layers of information. The TOTeM project used Internet of Things technologies to associate second-hand products in charity shops with stories of previous ownership [6]. The Significant Objects project explored how thrift store products could dramatically increase in value when

Permission to make digital or hard copies of all or part of this work for personal or classroom use is granted without fee provided that copies are not made or distributed for profit or commercial advantage and that copies bear this notice and the full citation on the first page. Copyrights for components of this work owned by others than the author(s) must be honored. Abstracting with credit is permitted. To copy otherwise, or republish, to post on servers or to redistribute to lists, requires prior specific permission and/or a fee. Request permissions from Permissions@acm.org. associated with fictional stories [20]. The Carolan acoustic guitar progressively acquired multiple and personalised layers of digital information as it passed among players [8]. A study of the lives of wargaming miniatures revealed how physical models became associated with digital stories of their making and use over their lifetimes [14].

There are also indications that the value of digitally-native products can be enhanced by associating them with physical materials. While online availability has transformed the distribution of music, there has been a parallel upsurge of interest in vinyl. Perhaps physicality remains an important aspect of experiencing music, adding value to what is otherwise cheaply and digitally available on the Internet?

Inspired by these observations, we explore how physicaldigital hybridization enables products to acquire value as they pass along a value chain from manufacturer to consumer. We use the term hybrid product to refer to physical-digital artefacts that are manufactured, distributed, sold and consumed. We are interested in how their hybridity enables physical and digital customization by various stakeholders that progressively adds value to them.

A second key idea that underlies our paper is therefore that of customization. This is traditionally an important driver for differentiating and adding value to products [28]. The related concept of personalization (in which products are automatically tailored by algorithms rather than being manually tailored as they are with customization [3, 36]) underpins many digital services, notably social media. As we shall discuss further later, customization has been a longstanding concern of HCI, from tailoring office software [30] through to making, crafting and hacking [25].

In what follows we explore how hybrid products can be physically and digitally customized. What kinds of physical and digital customization are possible? How might they add value? Who might undertake them, why and on behalf of whom? And how might we design hybrid products to be open to customization? We report on a technology probe a paper-based hybrid product in the form of a customizable advent calendar. We reveal how different stakeholders customised its physical and digital aspects in various ways, some anticipated, but others surprising. Our findings inform new concepts to help understand and design for hybrid customization - the idea of broad customization; end-toend customization; and the combination of these into customization maps. 


\section{METHOD}

We follow the method of technology probes. According to Hutchinson et al., a technology probe is an "instrument that is deployed to find out about the unknown - returning with useful or interesting data" [22]. A technology probe embodies a specific design idea within a prototype, embedding inspiration within design rather than providing inspiration for design as is the case with cultural probes [19]. The prototype is then deployed in real contexts so as to engage users in a design discussion. Hutchinson et al. maintain that technology probes should balance three broad goals: the design goal of inspiring reflection on emerging technologies; the social science goal of appreciating needs and desires; and the engineering goal of field-testing.

We alighted on the idea of a 'hybrid advent calendar' as being a suitable technology probe for exploring the question of how to customize hybrid products. Traditional physical advent calendars are extremely commonplace and widely consumed items while online digital calendars have grown in popularity over recent years, providing a clear motivation for considering some kind of hybrid product that could bring the two together. We hoped that, as a Christmas novelty, the calendar would be sufficiently lightweight and fun to attract people to easily engage on a first encounter. At the same time, we also hoped it might lead them into deeper engagement over a period of a month or so. Finally, the combination of a simple paper product and a mobile app meant that we could deploy our probe at a reasonable scale.

We designed the calendar and developed the app over the Summer of 2016 through an iterative dialogue between an artist, technical developers and researchers. Deployment began in November, using various channels to engage users including directly selling it online, running workshops at a local craft shop and a museum, running further workshops at the Mozfest festival and at a major media organization, and giving it away as a Christmas gift.

In methodological terms, the advent calendar was also chosen to address Hutchinson et al's requirements that a good probe should be simple yet flexible, open-ended, coadaptive (i.e., adaptable by researchers and users) and should yield useful data. The technology is relatively straightforward, combining a simple paper product with a downloadable mobile phone app, making it widely deployable and usable for general consumers (with some challenges that we discuss later). At the same time, its content can be surprisingly complex and open ended, potentially involving the creation of and scheduling of 24 physical and/or digital items. It therefore allows for extensive co-adaption, with users being able to adapt both its physical and digital forms in various ways. The calendar also yielded rich data in terms of application logs of patterns of use as well as many design ideas created by users, alongside a series of interviews and observations from workshops.

\section{DESIGN OF THE HYBRID ADVENT CALENDAR}

Physically, our advent calendar took the form of the cardboard structure shown in Figures 1 and 2 that arrived in an A3 envelope. An introduction and instructions were provided on the outside of two cardboard flaps (with links to a website for further instructions), which opened out to reveal a Christmas scene that spread over two A3 pages. The calendar came with 24 stickers (Figure 3 ) that could be placed under its 24 doors. The idea behind using stickers was to offer a simple entry-level step to customization while also allowing the calendar to be assembled at a time of its owner's choosing: perhaps in one or more sessions prior to the Advent season, or a day at a time during the 24 days leading up to Christmas, or some combination.

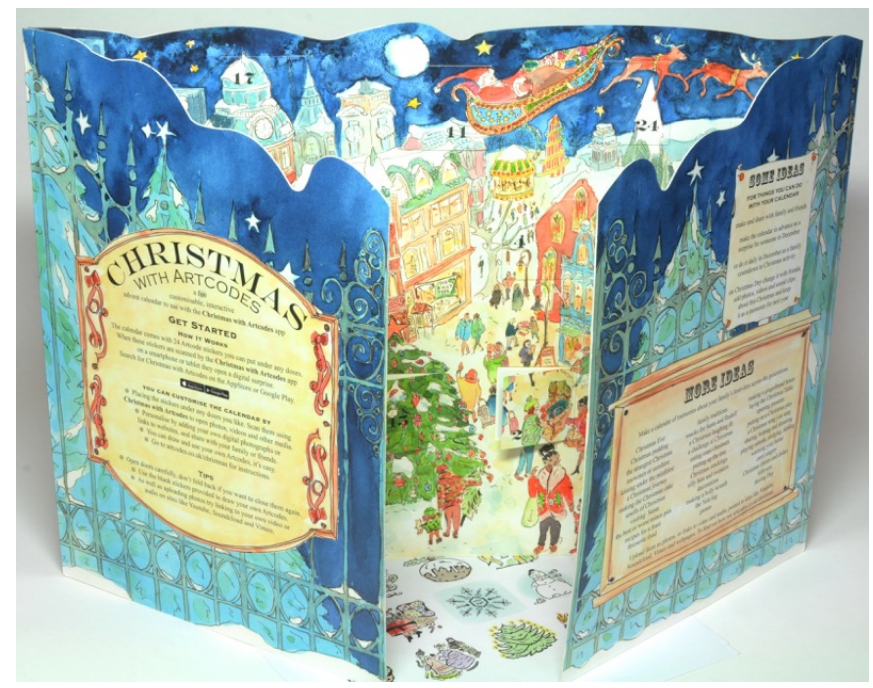

Figure 1: The Advent Calendar out of the envelope

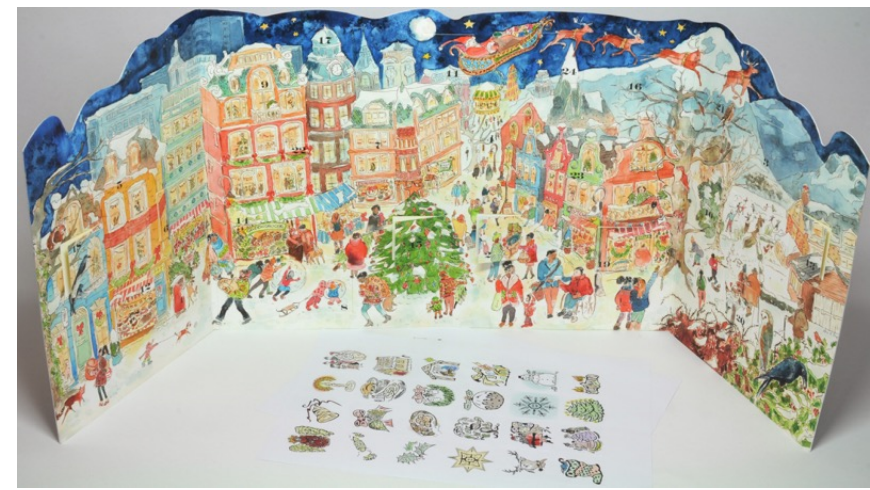

Figure 2. The Advent Calendar opened up

Each sticker was a visual marker realised using the Artcodes [31] implementation of Costanza's D-Touch technique [13]. Artcodes allows people to draw their own markers and so sheets of blank stickers, as well as links to instructions and tutorials, were provided so that owners could learn to draw their own designs, rather than use our default ones, as a further act of customization.

The calendar came with a bespoke app (Figure 4), available via Google Play and App Store, for scanning the stickers. 
By default this took the user to a series of Christmas themed and freely available webpages that we had curated from the Internet including: links to Christmas songs, animations, classic movie clips, jokes, games, puzzles and suggestions for seasonal cooking and crafting activities. Scanning a sticker also revealed an option to customize its content by providing a URL or uploading a photo from the phone. The resulting customizations were stored in a local version of the calendar (a layer of links to content) called 'My Calendar'. This layer could be shared with other people as a link embedded into email, text and social media. Incoming calendar layers from other people were added to a local list of available calendars and could be re-shared with others. In this way, calendar owners could customize its digital content and share it with others. We also provided a web-based editor for creating and sharing layers.

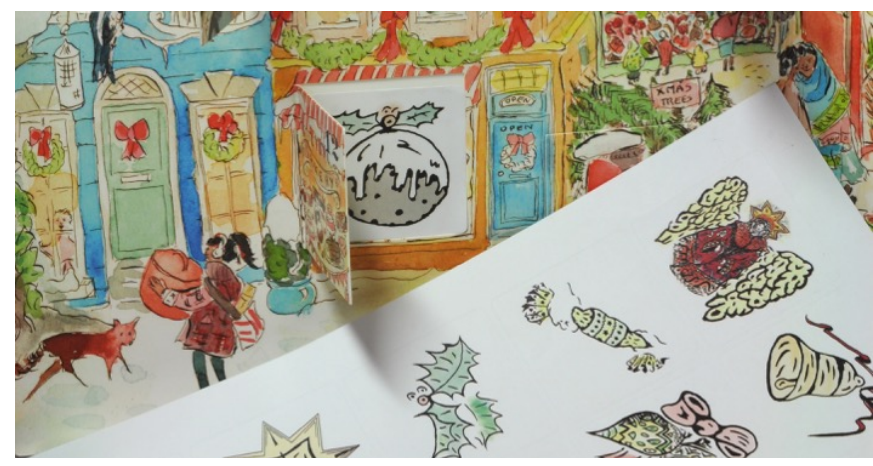

Figure 3. Placing the stickers under to doors.

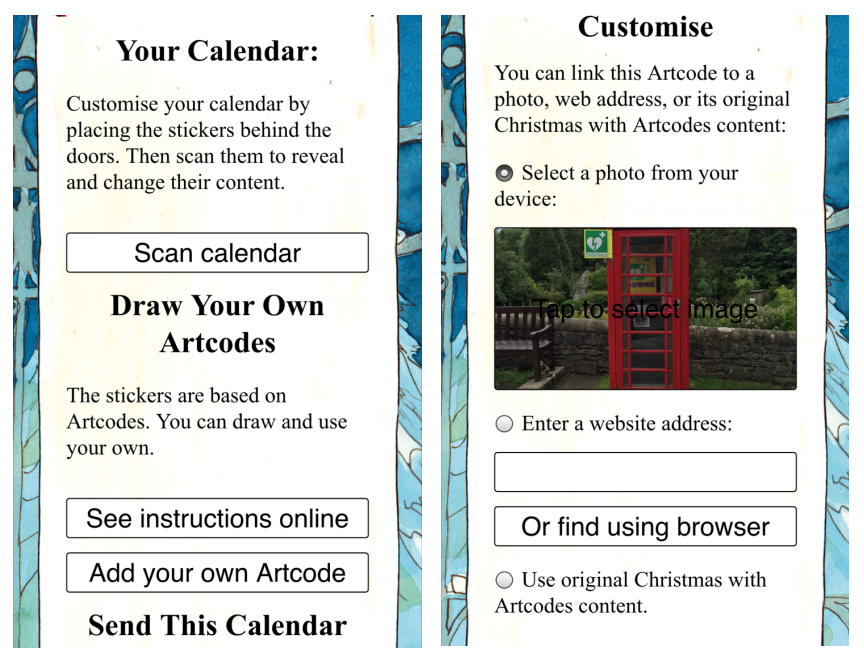

Figure 4. Customizing the calendar's digital content

In summary, our Advent calendar was a simple hybrid product - a traditional paper calendar connected to webpages and photos - that was designed from the outset to be physically and digitally customizable by arranging stickers, drawing stickers, and configuring and sharing layers of content.

\section{DEPLOYING THE CALENDAR}

We now describe how our advent calendar was deployed as a technology probe and experienced by hundreds of people.
Deployment began in mid-November and involved selling the calendar as a product on the Etsy online store (13 sales at a price of just under \$20), running workshops for the public at a local craft shop, a local museum, the Mozfest festival, and at a major media organization, and distributing the calendar as a promotional Christmas gift to friends, colleagues and sponsors much as one might do a corporate Christmas card. We distributed over 500 calendars in total. We then gathered data to reveal how people had experienced our calendar including:

- application logs gathered from the app (for users that gave consent to logging) that paint a broad picture of how and when people interacted with the calendar;

- an anonymous survey questionnaire distributed to active users to provide further insights as to their thoughts;

- interviews at the workshops and with other notable users to document particularly interesting use cases.

We now consider each of these three kinds of data in turn.

\section{How People Used the Calendar in General}

We gathered application logs from 209 devices that had actively used our app to interact with some Artcodes (excluding those from the immediate research team). Some people may have used multiple devices with their calendars while others may have engaged with the calendars (including as purely passive traditional Christmas decorations) without yielding logs. Consequently, we estimate a community of around 200 active users. These 209 devices engaged in 2867 scan events in which an Artcode was scanned, 789 customise events in which digital content was changed, and 109 share events in which a digital customization was shared with other devices.

\section{When Did People Use the Calendar?}

Figure 5 reveals the pattern of interactions over time, classified into scan events, customization events and share events. This shows a few interactions in mid November, growing over the last week of November, the most use in the first week of December, but then considerable ongoing use after that, including some into January. The various workshops drove interactions, but there is also a notable spike at Christmas Eve by which point the research team were on holiday, suggesting that some users continued to interact with the calendar under their own steam.

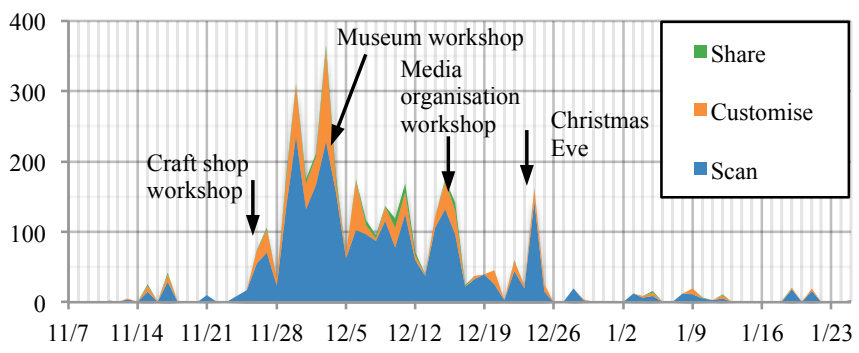

Figure 5. Use of the app over time 
What Did They Do with the Calendar?

In order to give some insight into the different types of users, Figure 6 shows the numbers of devices that engaged in different kinds of interactions with the calendar. 196 devices scanned the default codes. 86 were used to customize the digital content. 24 scanned custom (i.e., hand-drawn) codes. 51 devices were used to share custom digital content with others while 42 were used to access customized content that had been shared with them by others. There are some interesting partial overlaps between these. There appears to be a generally nested relationship between scanning, customizing digital content, and drawing and scanning custom codes. Sharing then cuts across these categories with devices being used to share default content, custom content and content associated with custom codes.

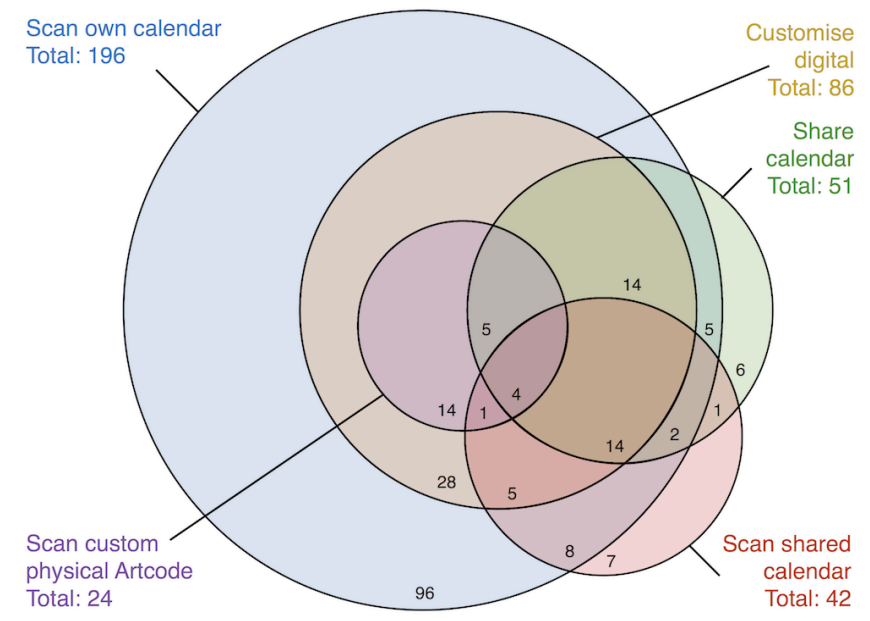

Figure 6. How devices interacted with the calendar

How Did They Customise the Calendar?

In terms of customizing digital content, of the 789 logged customize interactions, 437 involved uploading digital photos while 332 involved pointing a code towards a new website. In terms of pre-made versus user-drawn codes $91 \%$ of all scan events applied to pre-made codes, whereas $9 \%$ applied to user-drawn codes. The same percentage split applied to customisation events, i.e., $91 \%$ of customisations applied to pre-made codes and $9 \%$ to user-drawn codes.

\section{How Did They Share the Calendar?}

We now consider the relationship between customisation and sharing. Each column in Figure 7 represents a unique calendar layer that was shared with at least one other device. The vertical axis represents the number of codes that had been customized in the layer, ranging from 0 (an existing layer was shared) to 24 (all codes were changed to make a complete custom layer of content) while the colours show the balance of photos and website URLs in the customization. 68 unique layers of content were shared (the number of shared events rises to 116 when we include layers that were shared multiple times without changes). Around a third of these involved no customisation, a third involved just a few codes ( 1 to 3 ) being customised and the remaining third 5 or more. 11 layers involved 23 or 24 codes being customised. The more customised layers tended to be predominantly either photos or URLs, i.e., fulllayers tended to be customised in a consistent mode.

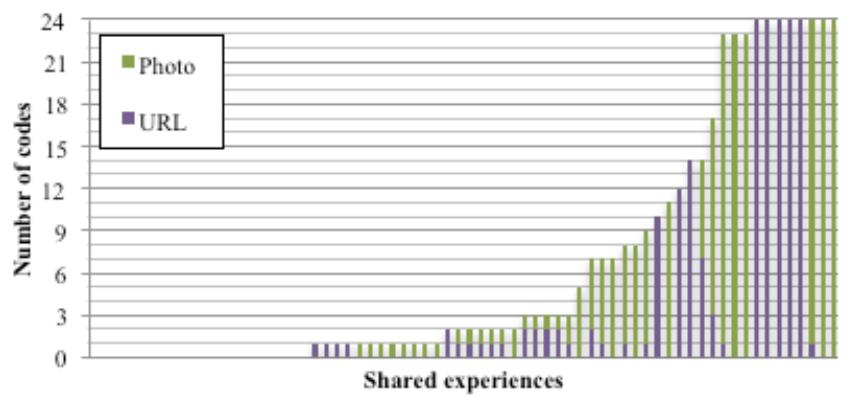

Figure 7. The compositions of customized and shared layers

\section{User Experience of the Calendar}

While the application logs reveal broad patterns of use, we need to turn to the survey and interviews to understand how people experienced the calendar. 36 participants responded to the survey which asked: Did they use the calendar and why? Would they use it again? What were the positive and negative aspects of the experience? Did they customize the calendar in various ways and if so, how and when? Did they share it and if so, with whom and why? And did they have any suggestion for extending it? We recognize that this selfselecting sample of all calendar users may be biased towards those who had a particular kind of experience, for example a positive one. Moreover, the anonymous survey did not identify participants or their relationships to the researchers so that respondents might include colleagues, friends, and family (though not the immediate research team). Our intention is therefore not to make claims about the quality of the probe, but rather to tease out further detail that relates to its customization as a hybrid product.

\section{Overall Use of the Calendar}

30 out of the 36 respondents reported using the calendar. Of the 6 who didn't, several were workshop participants who may have used it at a workshop but not subsequently. A couple noted that it had arrived too late in the season, while interestingly one (P34) claimed to be overwhelmed by the proposition: "I was overwhelmed by the choices offered and wasn't sure where to start. It seemed like I should start sticking the stickers in places of my choosing but couldn't understand what should guide those choices. I also got the impression that I could add any content I wanted to each sticker: this seemed an enormous challenge."

In order to use the calendar, some level of preparation was required by all participants. 15 reported making their calendars in one sitting (including P19 after Christmas ready for next year), 2 made it on a daily basis, 4 in bursts over a few days and 3 with a mixed pattern. The most common reasons for customizing the calendar were to make something special for family and friends. P18 reported their motivation to "create a timeline. We then viewed it all again on Christmas Eve" while P19 wanted to create a 
"Christmas memoire to look back at next Christmas". 19 respondents said that they would use the calendar again next year, 5 said they would not, 6 said they would but with caveats (if they had time and/or wifi) while 6 did not reply. One participant specifically noted reusability as one of the aspects they most liked about the calendar: "I like that it's reusable and could be used year after year" (P12).

\section{Experience of the Physical Artifact}

Participants generally appreciated the physical appearance and artwork of the calendar with 11 reporting this as the aspect they enjoyed most, e.g., "The artwork of the calendar and app are wonderful! Very much liked the watercolours and overall style" (P16), though one person noted that it wasn't to their taste: "I'm not a big fan of advent calendars and the aesthetics of the calendar is not to my taste" (P34).

All participants had to engage in a level of physical customization by placing the provided stickers under the doors. Several respondents specifically mentioned the stickers as a positive aspect of the calendar: "The kids love stickers, so were very happy to pick one each day to stick onto the calendar" (P18). However, there were also occasional frustrations about the "UX" of the physical calendar and stickers: "If stickers were slightly smaller or round would be easier to position (P12) and "The doors were hard to close afterwards" (P20). The lack of an inherent ordering of the stickers was also an issue for some (in cases where a digital layer was made to be shared with others who had their own physical calendar): "At first I was thinking of making a layer that should be revealed in a certain order, but that wouldn't work because the stickers would be placed randomly" (P23). 15 participants reported going further in physical customisation by trying to draw their own codes, 18 said they did not and 3 did not respond. 5 highlighted drawing their own stickers as one of the highlights: "we enjoyed having a go at drawing our own" (P17). One motivation was to enable the creation of other interactive Christmas artefacts beyond the calendar: "we want to make our own greeting cards using them but haven't done that yet" (P21) and "I made 2 Christmas cards and put a couple in my advent calendar" (P25).

While drawing was engaging for some, it was a tricky proposition for others: "I found the instructions to drawing your own confusing... but I must admit that I didn't spend a lot of time reading it... and I didn't try drawing one as it was so hectic at Christmas!" (P10). P10's comment also reflects others' about how customizing the calendar in general was time consuming: "took quite a while to make it all work together" (P6). People were also inhibited by a perceived lack of drawing skill, especially in relation to the supplied artwork: "My general inability to draw" (P26) and "it's hard to draw my own when the art already in there is so beautiful!" (P5). There were some suggestions of ways to overcome the challenge of drawing while still enabling customization: "offering in-app purchases or somewhere the ability to chose from premade art sets for the stickers or some kind of templates that rough in the basic images etc or what they link to and people can quickly customize / finish them for a person if gifting the cal" (P16). Interestingly, P36 wanted to make the calendar frame for themselves rather than the stickers: "I would like to have had more sticker sheets so I could make a calendar frame myself without having to compose the artcodes".

\section{Experience of the Digital Layer}

5 participants explicitly mentioned revealing digital content as the aspect of the calendar they enjoyed most: "Enjoyed finding out what each picture was going to take us to" (P10) and "I like the idea of sharing images, etc. versus objects or chocolate" (P12). Perhaps inevitably, a few found the visual marker technology challenging: "Sometimes took a while to detect sticker" (P2) and "Sometimes the app wouldn't recognise them and I couldn't figure out why" (P25), though it appears to have worked sufficiently well for most. 19 reported customizing the calendar to point at their own content, 9 said they did not and 8 did not respond. 5 mentioned enjoying discovering their own content, e.g.: "wandering around town looking for images that would be appropriate for each photo/topic as well as pictures I had on my computer from my home in the Yukon" (P9). Photos were popular: "Because it was Christmas I was taking pictures of the city, lights, people, food, office parties etc so that felt more relevant and personal to include" (P11), "photos of our family, in a timeline getting more recent as we went through advent" (P18), "my own photos from a current artists residency location in Spain" (P9) and "photos of my wife's works, watercolour paintings and links to her website and blog" (P13). While most participants did not have issues with customising the digital layer through the app, there was a suggestion for improving the interface: "there should be 2 clear modes: creation and then viewing. The viewing should be dead simple. Creating new content can be accessed away from the main interface since it's probably a one time thing" (P12).

\section{Sharing the Calendar}

Finally, in terms of sharing, 11 said they did share the physical or digital calendar they created, while 21 said they did not and 3 did not respond. Family and friends were mentioned as common targets. Sharing could be local (6 participants) by scanning a calendar using a shared device (which will not appear in the application logs considered above) or remote (6 participants) by sending a link to the digital layer, while 3 participants reported doing both. Several mentioned how they valued sharing calendars with remote friends and family: "friends who were at different uni's so quite spread out" (P1), "Those not in my own home who I haven't seen in ages" (P6) and "I shared it with people from far away. As a university student, I circulated it around to other university students." (P23). 5 highlighted the positive aspects of a shared experience: "I really liked receiving content from other people and being able to see 
what they'd created" (P23), "Being able to see pictures and links from my friends" (P2), and "My daughter and I enjoyed being able to have a special advent calendar creation moment together" (P17)).

\section{Specific Examples of Use}

We conclude our findings with some detailed examples of specific ways in which people customized the calendar.

\section{The Calendar as a Social Medium}

We have already seen above how one popular use was for sharing memories with distant family and friends. A university student (a family member of one the research team) used the calendar to communicate with his friends. He created his own full layer ( 24 days) of digital content comprising a series of images with captions showing events, funny things that happened over the year that he knew his friends would be interested in. He observed that it would have been useful to assign more than one piece of content per sticker - e.g. three things on each day ("the good, the bad and the ugly") - revealing a potential need for greater support for scripting media interactions. He used the pre-drawn stickers and assumed that his friends would choose them in random order (the group did not explicitly coordinate over how to use their calendars), which further limited the kinds of digital stories that he could tell to ones in which individual content could be experienced in any order. While some of his friends did not appear to engage with the calendar, he received a full layer in return from one of them comprising 24 photos that showed what their group had been up to during the year. He scanned his own calendar every few days to reveal these layers and was not interested in the default content.

\section{The Calendar as a Craft Kit}

The various crafting workshops highlighted a quite different sense of the calendar as product - this time as a craft kit. One such workshop took place at a craft shop over a period of two hours and involved 5 members of the public, all female with ages ranging from late 20s to early 50 s and from a variety of backgrounds: a business owner (spiritual coaching), beauty therapist, home maker, data analyst, shop manager. The primary focus of this workshop was on physical drawing and making rather than digital content. Participants spent a large part of the workshop learning to draw their own codes, experimenting with various Christmas themed designs. They suggested adding physical templates that people could colour and embellish as a halfway house between using provided stickers and drawing own from scratch. Although not creating digital layers during the workshop, they raised many ideas including revealing a gift each day (a mix of digital and physical experiences), Christmas around the world, getting ready for Christmas (a suggested activity for each day), a memory calendar and a 'craft calendar' linking to ideas for craft activities. One participant said she would finish it off that same afternoon and give it to her teenage daughters who had complained it was too boring when she had given them traditional calendars. Another would give it as a present for her dad (who got a smartphone recently and this would be a nice introduction to get him to use an app).

By way of contrast our second example focuses more on the crafting of the digital experience of the calendar and involved a family who were friends of one of the research team, comprising two parents in their 30s and children aged 7 (boy) and 2 (girl) who made and used a shared family calendar throughout the advent period. The activity was coordinated by the parents who systematically made use of two digital layers of content, the default one that we provided and a custom one comprising photos of the children (always showing both of them) following a timeline from being babies to present day over the 24 advent days. Each layer was on a different phone - the default on dad's and the custom on mum's (who configured the content). Each day the children took turns picking a sticker to put behind the door of the day. They then scanned the sticker with the dad's phone to reveal the default content while the mum quickly associated a photo with the chosen sticker in the custom layer using her phone. They did not draw any codes of their own as they did not find the time but the mum thought that her son would have enjoyed the activity. In response to the question of whether the default content is needed she said "I would have been putoff if there is nothing there" and suggested that as a solution some content from a pre-prepared selection could be randomly assigned to new (hand drawn) codes.

\section{The Calendar as a Media Campaign}

Our final examples concern the use of the Calendar as an official media channel by various organisations. The marketing department of our own University became interested in the calendar as the basis for running a seasonal promotional campaign, having already had the idea of publishing a series of blog posts as an online advent calendar. This inspired them to create 24 posts in which different members of the University were filmed opening the calendar, scanning content and then using this to talk about themselves. Links to these 24 blog posts were compiled into a full custom layer for the calendar itself and shared through the app. Our national research funding body also run an advent blogging campaign, featuring a different science and technology research story on their website each day. Again, a content layer was created by them that linked to the blog posts and was shared via the app.

We also ran workshops at two major media and cultural organisations who both discussed the possibilities of creating custom content layers for the calendar. In one case these might involve themed material from particular TV programmes. In the second, a custom layer was created with each sticker linked to a different digitized artwork from their collection with a suitable Christmas connection. The University, Research Council and Gallery layers were made available as 'featured layers' on the calendar's website that calendar owners could download and try out. 


\section{DESIGNING FOR CUSTOMISATION}

We now reflect on the experience of designing and deploying our advent calendar as a technology probe. Our discussion unfolds in three parts. First we consider the breath of possibilities for customization across both physical and digital. Then we consider the end-to-end nature of customization as different stakeholders along the value chain for a product add value by customizing it. Finally, we combine these two ideas in the form of customization maps that encourage reflection on the various ways in which a hybrid product might be customized.

\section{Broad Customization of Both Physical and Digital}

HCI has a longstanding interest in various forms of customisation. In an early contribution to the field, Mackay explored why and how users chose to customise (or not) software tools in the workplace, documenting various triggers to customization such as external events (job changes, office moves), social pressure from colleagues, changes in software (upgrades, breakdowns), and internal events (boredom, spare time and sudden insights) [30]. She also identified barriers such as poor documentation, the system being difficult to modify, lack of time, the risk of breaking the system, and being rooted in old patterns. Dyck and colleagues subsequently revealed how computer games are a form of software product that supports deep customisation in terms of players routinely moving interface elements around, extending functionality through macros, and also porting mods between games [17]. Related research has focused on the issue of appropriation. Dourish notes how people adapt technologies during the course of practice [16] in order to bridge what Ackerman refers to as the social-technical gap [1]. Dix celebrates appropriation as supporting situatedness, dynamics and ownership [15]. Carroll and colleagues considered how processes of appropriation, nonappropriation and disappropriation transition technologies between being designed, in-use and rejected [11]. From the physical perspective, HCI's turn to the material and the embodied has led to an interest in making, crafting and product hacking that may all involve elements of physical customization of existing artefacts [2, $12,35,38]$. With specific reference to hybrid (i.e., physicaldigital) products, [8] introduced the Carolan acoustic guitar that used augmented reality to connect its decorative inlay to digital documentation of its making and use. Their study revealed how the research team repeatedly altered the mapping between its physical and digital aspects as it travelled between different 'custodians', thus customising the digital content to fit the people and contexts.

We suggest that our advent calendar reveals broad (rather than deep) customisation, by which we mean it is open to a wide range of customizations across both its digital and physical aspects. Digitally, users can select which layer of content they wish to associate with the calendar at any moment in time and can also create their own layers and appropriate (adapt) those created by others. However, they cannot easily change the appearance or behaviour of the mobile app (without recourse to the open source code), so the calendar does not yet support the kind of deep software customization reported in [17]. Physically, users can customise the calendar by choosing under which doors to place the stickers, but can also learn to draw their own stickers and can make other artefacts, such as Christmas cards that will work with the app.

\section{Possibilities for Customization}

Generalising away from the calendar somewhat, we can consider the idea of broad customisation as defining one dimension of customization of hybrid products (see Figure 8). In the figure we have abstracted both ideas from the literature and specific lessons of the calendar into more generic terms for customization that might potentially be associated with a wider range of hybrid products. We have then aligned these with a dimension that runs from digital to physical, so that deeper forms of customisation are generally to be found at the extremes of the dimension.

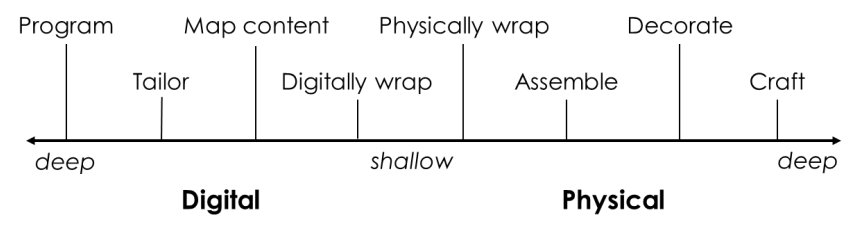

Figure 8. Broad customisation of hybrid products

At the extreme end of digital customization lies programing including scripting and the use of macros, while less extreme is being able to tailor the interface and functionality [17], for example through using menus of preferences although including the kinds of deep customization reported for computer games [17]. Next, is the ability to change digital content, including uploading one's own, which in the case of hybrid products specifically, includes customizing the mapping between digital content and physical artefacts as described in [8].

Towards the middle of the dimension we have introduced digital wrapping and physical wrapping as forms of customisation. Gift-wrapping is a familiar, easy and socially important way of customizing products to make them more meaningful to others and also to show effort and care in the giving of the gift. Wrapping can clearly be physical, covering the product in one or more aesthetically pleasing layers of material and perhaps associating it with a personal message, something that would be easily possible when giving the calendar as a gift. Kwon et al. have also proposed digital wrapping, in which a product (potentially digital or physical) might be wrapped in layers of digital media, in response to the findings of their study that both givers and receivers felt far less engaged through the entire process of preparing, exchanging, unwrapping, using and reflecting on digital gifts (digital products given online) compared to physical ones [26].

Moving into the physical end of the dimension, customers may configure their product during physical assembly, in 
our case by assigning their stickers to the doors. Tangible interfaces may be open to a degree of assembly [39], which may provide ample opportunities for customization. Surface decoration is a common way of customizing possessions, from wallpapering our homes to stickering our laptops, and in the case of the calendar also drawing our own stickers. The emergence of augmented reality also brings new opportunities to decorate objects with interactive patterns [7]. Finally, we may deeply craft (or make, or hack depending upon the context and our intent) the underlying form, structure, and function of the product [21].

Thus, in seeking to customize a product, or indeed to design it to enable customization, one might start with an uncustomized product at the centre of our dimension and then progressively deepen customisation by moving towards one or both of its ends.

\section{End-to-end Customization Along the Value Chain}

The above discussion adopted a largely technology-oriented stance to the challenge of customization. As an alternative, this section adopts a more human-centred perspective, considering the different stakeholders that can be involved in customizing a hybrid product and the ways in which they may add value to it. We propose that, as well as broad customization, our advent calendar also supports end-to-end customization, by which we mean that various stakeholders involved in its production, distribution and consumption are able to customise it as it passes along the value chain [24, 32] from manufacturer to consumer. Our initial conception of the calendar was that we (taking on the role of manufacturers) would create and distribute it to our participants who (as consumers) would then be able to customize it in various ways. However, the data returned by our probe revealed a more complex picture in terms of the stakeholders involved. First, it was striking how a minority of customers took a lead role in customizing the calendar for and with others, for example working with their children to make and deliver a calendar experience or creating layers of content for a group of friends who also owned calendars, as described in the vignettes above. Second, we saw the emergence of organisations that wished to distribute their own full-layers of custom content to their own customers, most notably as part of campaigns. These reflections lead us to articulate the dimension of end-to-end customization as shown in Figure 9. This runs along the value chain for the hybrid product and considers the key stakeholders who might be involved in customizing it along the way.

Again, abstracting away from the specifics of the advent calendar, we have labelled this with four, more generic, categories of stakeholder:

- Manufacturer - in this case our team who made the baseline physical calendar, stickers and default content.

- Distributors - organisations or individuals who would customize complete layers of content for the calendar for the purposes of addressing their own audiences, potentially also repackaging the physical calendar, e.g., the two blog campaigns and gallery layers.

- Prosumers - those people who engaged in significant customisation, often on behalf of or with others. They include people who adapted its content for remote friends, or who worked with their children to customise the calendar or who even made their own physical stuff. They include crafters and makers - and possibly hackers - but also people who engaged in more straightforward acts of linking the existing calendar to photos or websites of their choice. We choose the term 'prosumer' [34] to describe people who engage in both production and consumption to describe this category as a whole.

- Consumers - those who engaged with the calendar without changing its content or fundamental physical design or form, i.e., who were happy to scan the stickers to reveal content that had been created for them. Even then, many consumers will have engaged in a relatively small degree of customization by choosing which stickers to place under which doors.

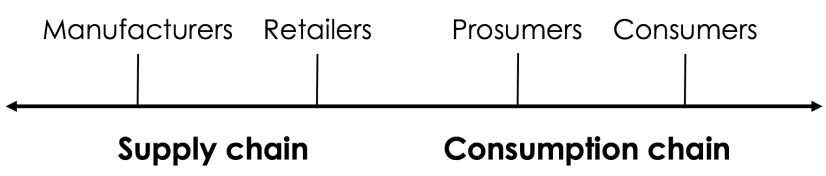

Figure 9. End-to-end customization of hybrid products

How Customization Adds Value

By customizing the product in different ways, each of these stakeholders adds various forms of value. The question of value in relation to products has long been discussed in the marketing literature. Zeithaml's review from 1988 considers value from a largely monetary perspective: as price; as 'what I get for what I give'; as a trade-off between price and quality; and as an overall assessment of objective worth [42]. Later definitions considered the utilitarian and hedonic values that arise from shopping [5] while Rintamäki's study of department store shopping extended these with the further category of social value [33]. Research from the field of business and management discusses value chains in which products pass through various activities - logistics, operations, service, sales and marketing - that add value to them along the way [32]. Where production is distributed among manufacturers, it is common to talk of supply chains, with each company in the chain bringing value to the product. This has been extended with the notion of consumption chains that consider value from the customer's perspective, emphasising the total product and the overall 'customer journey map' [24].

Turning back to HCI, studies of maker communities have revealed alternative kinds of value associated with DIY practices including the pleasure of making, personal expression, and also the potential democratisation of the production process. Kuznetsov et al's survey of over 2600 members of DIY communities reveals how they value open sharing, learning, and creativity above social capital and 
profit [25]. Others have argued how hackerspaces are experimenting with new models of manufacturing and entrepreneurship that need to be taken seriously beyond their value as hobbyist or leisure practices [29]. In a different vein, Kwon et al explored the social value of gifting products, as described previously [26]. Tannenbaum has argued that such DIY practices bring the added value of democratising production [37].

We propose that, as a result of its support for both end-toend and broad customization, our advent calendar speaks to several of these different kinds of value. It is potentially a saleable product with monetary value, it delivers hedonic and social (more than utilitarian) value. In addition, for some there appears to be value in the DIY creativity of designing markers and making their own products such as Christmas cards. These different kinds of value accrue along a value chain in which manufacturers, distributors, prosumers and consumers each customize the calendar in their own ways. In turn, value can also potentially flow back along the chain too. Consumers may express gratitude or even reciprocate to the prosumers who shared with them as part of gifting. Manufacturers and distributers may harvest ideas for adaptations from the creativity of prosumers in the manner suggested by Lafreniere and Terry in their socially adaptable interfaces [27].

\section{Mapping Customization}

We bring our two dimensions together in the idea of a customization map as a way of charting out the various ways in which a given product offers customization to its different stakeholders. Figure 10 shows a customization map for the advent calendar. Breath of customization is shown horizontally while end-to-end customization is depicted vertically as a series of layers or shells. The radiating lines correspond to the different possibilities for customization, with digital radiating out to the left and physical to the right. They are marked to show the specific customization possibilities that are - or potentially might or might not be - supported by the product. In this case, we have done this to summarise our learning from the probe and to reflect on how the calendar might potentially be redesigned as well as how it was originally made. The markers (stars) in this example are binary - suggesting either customizable or not - but could be scaled in various ways to suggest a level of customization. We have therefore labeled the map with four types or marker:

- Possibilities for customization that were originally designed into the calendar. Reflection might consider to what extent these were successful and should be retained.

- Possibilities that emerged from experience with the calendar that we hadn't originally anticipated. Reflection can consider how these customer-led ideas might be better and more officially integrated into the product.

- Possibilities that we can imagine adding to the calendar to further extend its capability for customization.
- Possibilities that - while technically possible - are more questionable for some reason.

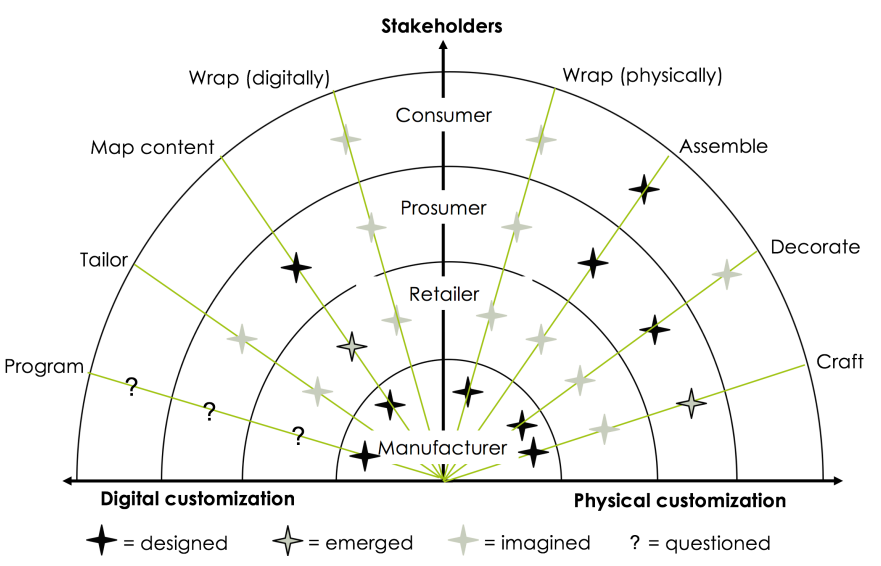

Figure 10. Customization map for the advent calendar

One notable feature of this map is that it reveals how the calendar provided multiple mechanisms at each layer to enable both physical and digital customisation. Manufacturers created the baseline calendar, default stickers and default content. Distributers were able to add their own layers of digital content, but might also presticker the calendar (to schedule the content to predefined days) and could potentially create their own custom sticker sets. Prosumers could map the calendar to their own photos or choice of websites, could learn to draw their own stickers or could craft new products such as cards. Consumers might choose the order of stickers and which content layers to make visible. We argue that the population of all four layers on both sides reinforces the view that the calendar was designed for both broad and end-to-end customization.

Our customization map also helps us envisage how the product might be redesigned. The emergent customization of retailers providing and distributing full layers of content would be further enhanced with additional tools and perhaps customizations of the calendar and its wrapping. Prosumers could be given more support for customizing its media types and scripting behaviors and be provided with some simpler project options to get started. There would appear to be also potential for supporting customized gift (physical and digital) wrapping of the calendar. And yet is more or unlimited customization always a good thing? Our experience of the calendar also told us that some people found it to be too complex a proposition and demanding of their time, which may be barriers to customization.

With this in mind, the map also provides an opportunity to reflect on areas that might not be prioritized. Is it worth, for example, the significant effort required to make the app more scriptable and programmable compared to addressing the challenges of making the calendar more physically craftable? Might allowing prosumers to hack the app's functionality somehow reduce the appeal to retailers of creating customized and commercially-branded layers, for example by potentially opening them up to hacking? 


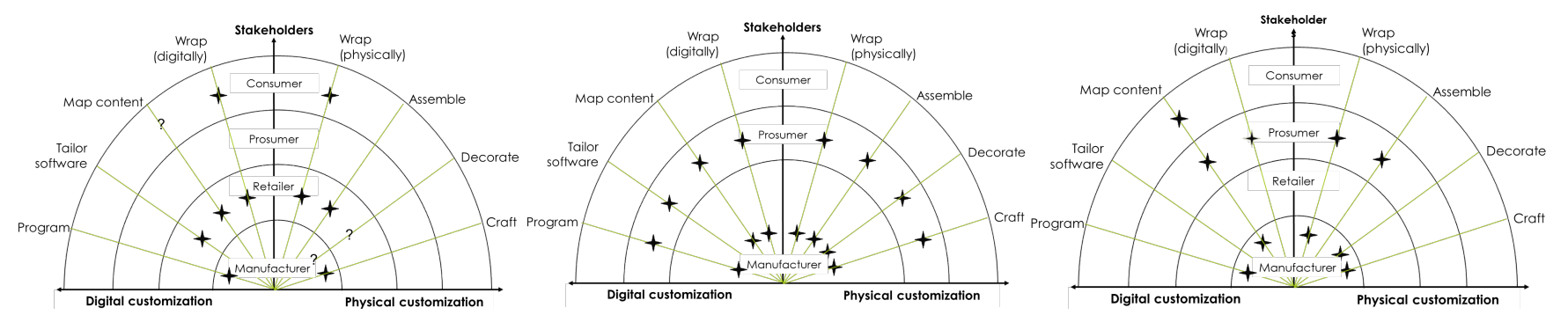

Figure 11. The calendar as a retailed Christmas product (left), craft kit (middle) and social media channel (right)

\section{Reimagining Products}

This leads us to a final use of customization maps, to help identify opportunities for new products to emerge out of existing ones. If we consider the view that the current calendar is already a complex proposition and combine this with the example uses that we reported in the earlier vignettes, we might consider dividing the current product into several new ones that address specific stakeholders and that focus solely on the kinds of customizations that they require. Figure 11 shows three further maps in which we explore potential designs for such products. The left one relates to a "story" or campaign calendar as a consumer Christmas product. The idea is to extend retailers' customization of branded layers to the app's functionality while better enabling consumers to physically and digitally wrap the calendar as a gift, perhaps personalizing some content, but with little emphasis on prosumers. The middle one transforms the calendar into a craft kit aimed at prosumers who are offered the full breadth of customization. The product would be framed as a making kit from the outset and might include greater support for templates, tutorials and perhaps smaller projects such as gift cards leading up to the Calendar as an extended project. Finally, the right one reimagines our advent calendar as a social media channel to share memories and other media. This might target a core prosumer who will coordinate the group activity - a parent for example - making it easier for them to map content and assemble the stickers into an order so that group members see the same content on the same days, and other group members (consumers) to map their own content in response. To determine if these are viable products would require greater market research, product testing and so forth. Our point however, is that mapping physical and digital customization in this way may highlight when there are too many possibilities and help to explore the possibilities for spinning off new products.

\section{CONCLUSIONS}

Even though our advent-calendar is a relatively simple paper-based example of a hybrid product, it has revealed a wide range of possibilities for customization. We saw broad customization of both its physical and digital aspects. We also saw end-to-end customization in which various stakeholders along its value chain added value. Drawing these two observations together led to the concept of customization maps as a way of charting the various ways in which a hybrid product might potentially be customized.
How might these ideas apply to other kinds of hybrid product, especially to more technically sophisticated ones? Consider the motorcar as an example. Cars have traditionally been physical products. However, over recent years they have become hybrid products, not only in the sense of hybrid engines, but also in the meaning of this paper - that they are now a mixture of physical and digital materials. The modern car includes a software engine management system as well as software services for navigation, communications and entertainment. Customization has long been part of the motor industry, from custom hand-built cars, to allowing consumers to choose their own interiors, fittings and options, to specialized custom shops. Customization can now be broadened to include the digital behaviour of the car, for example configuring different engine settings in software to provide sports or economy modes, and the possibilities will only increase as cars become more autonomous, including learning and adapting to their driver's behaviour. Applying the concept of custom maps to a car encourages one to consider a wide range of possibilities for both physical and digital customization and also which stakeholders along its value chain can undertake these. What do manufacturers customize? What further value might dealers add through further customizations and what can consumers customize for themselves? Equally, as car is a safety-critical product, unlike an advent calendar, what customization are not appropriate for different stakeholders?

It is beyond the remit of this paper to undertake a detailed analysis of this or other similar examples. However, by raising a somewhat extreme example of an emerging hybrid product we hope to suggest that the lessons learned from a simple paper-based technology probe may ultimately be more widely applicable to many future kinds of hybrid products that will soon enter our lives.

\section{ACKNOWLEDGEMENTS}

This work was supported by UK Engineering and Physical Sciences Research Council grant EP/M02315X/1 and by the EU Horizon 2020 grant 727040 (the GIFT project).

\section{DATA ACCESS STATEMENT}

Anonymous questionnaire data underlying this paper can be obtained from https://doi.org/10.5281/zenodo.1137055 


\section{REFERENCES}

1. Mark S. Ackerman. 2000. The intellectual challenge of CSCW: the gap between social requirements and technical feasibility. Human-Computer Interaction. 15, 2 (September 2000), 179-203.

http://dx.doi.org/10.1207/S15327051HCI1523_5

2. Morgan G. Ames, Jeffrey Bardzell, Shaowen Bardzell, Silvia Lindtner, David A. Mellis, and Daniela K. Rosner. 2014. Making cultures: empowerment, participation, and democracy - or not?. In CHI'14 Extended Abstracts on Human Factors in Computing Systems (CHI EA '14), 1087-1092. https://doi.org/10.1145/2559206.2579405

3. Neeraj Arora, Xavier Dreze, Anindya Ghose et al. 2008. Putting one-to-one marketing to work: Personalization, customization, and choice. Marketing Letters. 19.3-4, 305

4. Ronald Azuma. 2004. Overview of augmented reality. In ACM SIGGRAPH 2004 Course Notes (SIGGRAPH '04). Article 26. http://dx.doi.org/10.1145/1103900.1103926

5. Barry J. Babin, William R. Darden, and Mitch Griffin. 1994. Work and/or fun: measuring hedonic and utilitarian shopping value. Journal of consumer research 20.4 (March 1994), 644-656.

6. Ralph Barthel, Kerstin Leder Mackley, Andrew Hudson-Smith, Angelina Karpovich, Martin de Jode, and Chris Speed. 2013. An internet of old things as an augmented memory system. Personal and Ubiquitous Computing 17, 2: 321-333

7. Steve Benford, Boriana Koleva, Anthony Quinn et al. 2017. Crafting interactive decoration. ACM Transactions on Computer-Human Interaction (TOCHI) 24, 4, Article 26 (August 2017). https://doi.org/10.1145/3058552

8. Steve Benford, Adrian Hazzard, Alan Chamberlain, et al. 2016. Accountable Artefacts: The Case of the Carolan Guitar. In Proceedings of the 2016 CHI Conference on Human Factors in Computing Systems (CHI '16), 1163-1175. https://doi.org/10.1145/2858036.2858306

9. Steve Benford and Gabriella Giannachi. 2011. Performing mixed reality. The MIT Press.

10. Blaine Brownell. 2006. Transmaterial: A Catalog of Materials that Redefine our Physical Environment, Princeton Architectural Press

11. Jennie Carroll, Steve Howard, Frank Vetere, et al. 2001. Identity, Power And Fragmentation in Cyberspace: Technology Appropriation by Young People. ACIS 2001 Proceedings. 6. http://aisel.aisnet.org/acis2001/6

12. Amy Cheatle and Steven J. Jackson. 2015. Digital Entanglements: Craft, Computation and Collaboration in Fine Art Furniture Production. In Proceedings of the 18th ACM Conference on Computer Supported Cooperative Work (CSCW '15). 958-968. http://dx.doi.org/10.1145/2675133.2675291

13. Enrico Costanza and John Robinson. 2003. A region adjacency tree approach to the detection and design of fiducials. In Proceedings of Video Vision and Graphics Conference. 63-69.

14. Dimitrios Paris Darzentas, Michael A. Brown, Martin Flintham, and Steve Benford. 2015. The Data Driven Lives of Wargaming Miniatures. In Proceedings of the 33rd Annual ACM Conference on Human Factors in Computing Systems (CHI '15). ACM, New York, NY, USA, 2427-2436.

15. Alan Dix. 2007. Designing for appropriation. In Proceedings of the 21st British HCI Group Annual Conference on People and Computers (BCS-HCI '07), Vol. 2, 27-30.

16. Paul Dourish. 2004. Where the Action Is, MIT Press

17. Jeff Dyck, David Pinelle, Barry AT Brown, and Carl Gutwin. 2003. Learning from Games: HCI Design Innovations in Entertainment Software. In Graphics interface, vol. 2003, 237-246.

18. George W. Fitzmaurice, Hiroshi Ishii, and William Buxton. 1995. Bricks: laying the foundations for graspable user interfaces. In Proceedings of the SIGCHI Conference on Human Factors in Computing Systems (CHI '95), 442-449. http://dx.doi.org/10.1145/223904.223964

19. Bill Gaver, Tony Dunne, and Elena Pacenti. 1999. Design: Cultural probes. interactions 6, 1 (January 1999), 21-29. http://dx.doi.org/10.1145/291224.291235

20. Joshua Glenn and Rob Walker. 2012. Significant Objects. FANTAGRAPHICS, Seattle, WA.

21. Connie Golsteijn, Elise Hoven, David Frohlich, and Abigail Sellen. 2014. Hybrid crafting: towards an integrated practice of crafting with physical and digital components. Personal Ubiquitous Comput. 18, 3 (March 2014), 593-611. http://dx.doi.org/10.1007/s00779-013-0684-9

22. Hilary Hutchinson, Wendy Mackay, Bo Westerlund, et al. 2003. Technology probes: inspiring design for and with families. In Proceedings of the SIGCHI Conference on Human Factors in Computing Systems (CHI '03), 17-24. http://dx.doi.org/10.1145/642611.642616

23. Hiroshi Ishii and Brygg Ullmer.1997. Tangible bits: towards seamless interfaces between people, bits and atoms. In Proceedings of the SIGCHI Conference on Human Factors in Computing Systems (CHI '97), 234241. http://dx.doi.org/10.1145/258549.258715

24. Philip Kotler. 2012. Kotler on marketing. Simon and Schuster. 
25. Stacey Kuznetsov and Eric Paulos. 2010. Rise of the expert amateur: DIY projects, communities, and cultures. In Proceedings of the 6th Nordic Conference on Human-Computer Interaction (NordiCHI '10), 295304. http://dx.doi.org/10.1145/1868914.1868950

26. Hyosun Kwon, Boriana Koleva, Holger Schnädelbach, and Steve Benford. 2017. "It's Not Yet A Gift": Understanding Digital Gifting. In Proceedings of the 2017 ACM Conference on Computer Supported Cooperative Work and Social Computing (CSCW '17), 2372-2384. https://doi.org/10.1145/2998181.2998225

27. Benjamin Lafreniere, Andrea Bunt, Matthew Lount, Filip Krynicki, and Michael A. Terry. 2011. AdaptableGIMP: designing a socially-adaptable interface. In Proceedings of the 24th annual ACM symposium adjunct on User interface software and technology (UIST '11 Adjunct), 89-90. https://doi.org/10.1145/2046396.2046437

28. Jay Lee, Behrad Bagheri and Hung-An Kao. 2015. A cyber-physical systems architecture for industry 4.0based manufacturing systems. Manufacturing Letters, $3,18-23$.

29. Silvia Lindtner, Garnet D. Hertz, and Paul Dourish. 2014. Emerging sites of HCI innovation: hackerspaces, hardware startups \& incubators. In Proceedings of the SIGCHI Conference on Human Factors in Computing Systems (CHI '14). 439-448. https://doi.org/10.1145/2556288.2557132

30. Wendy E. Mackay. 1991. Triggers and barriers to customizing software. In Proceedings of the SIGCHI Conference on Human Factors in Computing Systems (CHI '91), 153-160. http://dx.doi.org/10.1145/108844.108867

31. Rupert Meese, Shakir Ali, Emily-Clare Thorne et al. 2013. From codes to patterns: designing interactive decoration for tableware. In Proceedings of the SIGCHI Conference on Human Factors in Computing Systems (CHI '13), 931-940. https://doi.org/10.1145/2470654.2466119

32. Michael E. Porter. 2008. Competitive advantage: Creating and sustaining superior performance. Simon and Schuster.

33. Timo Rintamäki, Antti Kanto, Hannu Kuusela, Mark T. Spence. 2006. Decomposing the value of department store shopping into utilitarian, hedonic and social dimensions: Evidence from Finland. International Journal of Retail \& Distribution Management. 34.1, 624, https://doi.org/10.1108/09590550610642792
34. George Ritzer and Nathan Jurgenson. 2010. Production, consumption, prosumption: The nature of capitalism in the age of the digital 'prosumer'. Journal of consumer culture. 10.1, 13-36.

35. Daniela K. Rosner and Kimiko Ryokai. 2009. Reflections on craft: probing the creative process of everyday knitters. In Proceedings of the seventh ACM conference on Creativity and cognition (C\&C '09), 195-204. http://dx.doi.org/10.1145/1640233.1640264

36. Sundar, S. Shyam, and Sampada S. Marathe. 2010. Personalization versus customization: The importance of agency, privacy, and power usage. Human Communication Research. 36.3 (July 2010), 298-322.

37. Joshua G. Tanenbaum, Amanda M. Williams, Audrey Desjardins, and Karen Tanenbaum. 2013.

Democratizing technology: pleasure, utility and expressiveness in DIY and maker practice. In Proceedings of the SIGCHI Conference on Human Factors in Computing Systems (CHI '13), 2603-2612. https://doi.org/10.1145/2470654.2481360

38. Vasiliki Tsaknaki, Ylva Fernaeus, and Mischa Schaub. 2014. Leather as a material for crafting interactive and physical artifacts. In Proceedings of the 2014 conference on Designing interactive systems (DIS '14), 5-14. https://doi.org/10.1145/2598510.2598574

39. Brygg Ullmer and Hiroshi Ishii, Emerging frameworks for tangible user interfaces, IBM Systems Journal, Volume: 39 Issue: 3.4, 915-931, 2000, IEEE

40. Anna Vallgårda and Johan Redström. 2007. Computational composites. In Proceedings of the SIGCHI Conference on Human Factors in Computing Systems (CHI '07). ACM, New York, NY, USA, 513522. https://doi.org/10.1145/1240624.1240706

41. Mark Weiser. 1993. Some computer science issues in ubiquitous computing. Communications of the ACM. 36, 7 (July 1993), 75-84. http://dx.doi.org/10.1145/159544.159617

42. Valarie A. Zeithaml. 1988. Consumer perceptions of price, quality, and value: a means-end model and synthesis of evidence. The Journal of marketing. Vol. 52 (July 1988), 2-22. 